\title{
A Survey of Licensed Massage Therapists' Perceptions of Skin Cancer Prevention and Detection Activities
}

\author{
Lois J. Loescher, PhD, RN, ${ }^{1 *}$ Amy L. Howerter, $\mathrm{PhD},{ }^{2}$ Kelly M. Heslin, MPH, ${ }^{1}$ \\ Christina M. Azzolina, MPH, ${ }^{2}$ Myra L. Muramoto, MD, $\mathrm{MPH}^{2}$ \\ ${ }^{1}$ College of Nursing, University of Arizona, Tucson, AZ, ${ }^{2}$ Department of Family and Community Medicine, \\ University of Arizona, Tucson, AZ
}

Background: Skin cancer is the most common cancer in the US. Training massage therapists (MTs) in skin cancer prevention and detection creates opportunity for reducing skin cancer burden. Little is known about MTs' perceptions of skin cancer prevention and detection, their discussions of these topics with clients, or their referral recommendations for suspicious skin lesions.

Purpose: We surveyed MTs' perceptions of their role in engaging in conversations about skin cancer prevention, viewing the skin for suspicious lesions, and referring clients with such lesions to health care providers.

Setting, Participants, Research Design: We administered an online survey from 2015-2017 of licensed MTs practicing in the US and at least age 21 years $(n=102)$; quantitative and qualitative data were analyzed in 2017.

Main Outcome Measures: The main variables assessed were MTs perceptions of (a) appropriateness for asking clients about skin cancer history, skin cancer prevention, suspicious lesion referral and follow-up; and (b) comfort with recognizing and discussing suspicious lesions, recommending a client see a doctor for suspicious lesion, and discussing skin cancer prevention.

Results: Quantitative data revealed that most MTs were amenable to discussing skin cancer prevention during appointments; few were engaging in these conversations. MTs were more comfortable discussing suspicious lesions and recommending that a client see a doctor than they were sharing knowledge about skin cancer and sun safety. Categories based on qualitative content analysis were: sharing information for the client's benefit, and concerns about remaining within scope of practice.

Conclusions: MTs have boundaries for skin cancer risk-reduction content to include in a client discussion and remain in their scope of practice. These findings will help support a future educational intervention for MTs to learn about and incorporate skin cancer risk-reduction messages and activities into their practice.
KEY WORDS: skin cancer prevention; survey of massage therapists; skin cancer education

\section{INTRODUCTION}

Skin cancer prevention and detection training of licensed service practitioners with "eyes on the skin," such as massage therapists (MTs), creates an additional public health resource for reducing the skin cancer burden in the United States. Skin cancer is the most common cancer in the U.S - about 5.4 million skin cancers are diagnosed each year in about 3.3 million Americans. ${ }^{(1)}$ Unlike other common cancers, skin cancer rates in the US have risen steadily in recent years. ${ }^{(2)}$ Skin cancer is also expensive, exceeding costs of $\$ 8.1$ billion annually in the US. (3) Most skin cancer can be prevented by reducing exposure to ultraviolet radiation (UVR), ${ }^{(4)}$ and by early detection to reduce morbidity and mortality. ${ }^{(5,6)}$ In 2014 , the Surgeon General of the United States issued a Call to Action to partners in prevention from various sectors across the nation to address skin cancer as a major public health problem. Partners essential to this effort include members of the business, health care, and education sectors, as well as individuals and families. ${ }^{(7)}$ Within this context, massage therapy can be considered a business - it was estimated to be a $\$ 16$ billion industry in 2017. ${ }^{(8)}$ MTs can be considered as potential partners to reduce skin cancer risk.

Skin cancer lesions are often visible on the skin to the naked eye and, thus, are amenable to early detection by a visual skin assessment (VSA) from a health care professional. The skin is assessed for sunburn and tanning, and "ugly duckling" or abnormal-looking skin lesions. ${ }^{(9)}$ VSA training traditionally has targeted medical practitioners, but its implementation by dermatologists, family physicians, and internists is less than ideal. ${ }^{(10)}$ Non-medical service providers recently have been more engaged in conducting and promoting skin cancer detection; however, these efforts lack systematic evaluation. ${ }^{(11,12)}$

Massage therapists are well-positioned to conduct VSA. The American Massage Therapy Association 
estimates that there are 335,000-385,000 MTs in the US. Licensed or certified MTs see about 39.1 million clients annually. ${ }^{(8)}$ These professionals have unique access to nearly all of a client's skin throughout the appointment. During a typical full-body massage, the client is unclothed and under a drape. MTs systematically undrape each body area to massage and then re-drape. Using this procedure, MTs view the skin in segments, allowing near whole-body VSA. They can note skin cancer risk factors such as sunburn, tanning lines, high mole counts, or suspicious lesions. Compared to primary care providers or dermatologists, MTs are more likely to have repeated and longer appointments that tend toward health promotion, ${ }^{(13,14)}$ thereby providing greater opportunities to see lesions on the skin over time. One study found that MTs provided overall wellness care at about $30 \%$ of their visits, while conventional physicians provided similar care not directly related to illness at about $18 \%$ of visits. ${ }^{(14)}$ Nevertheless, very little is known about MTs' perceptions of skin cancer prevention and detection, whether they have prevention-oriented conversations with their clients, or if they make referral recommendations for suspicious-looking lesions. We do know that MTs receive little-to-no content on skin cancer prevention as part of their basic MT education or through continuing education. ${ }^{(15)}$

The purpose of this study was to assess MTs' perceptions of their role in engaging in conversations about skin cancer prevention, viewing the skin for suspicious skin lesions, and referring clients with suspicious skin lesions to health care providers. Specifically, we sought to describe 1) perceptions of whether these topics were appropriate and comfortable to discuss during a client visit; 2) participants' client-related VSA activities, including recommendations and follow-up for suspicious skin lesions visualized during massage. We also explored participants' educational preparation for skin cancer prevention and skin assessment. This was a preliminary study to support a larger intervention trial to train MTs about skin cancer prevention and detection.

\section{METHODS}

The University of Arizona Institutional Review board approved this cross-sectional descriptive study; free and informed consent of subjects was obtained via a disclaimer prefacing the survey. We implemented an online anonymous survey of MTs using Qualtrics (Qualtrics, Provo, UT). We collected data between 2015 and 2017, and coded and analyzed the data in December 2017. The Strengthening the Reporting of Observational Studies in Epidemiology (STROBE) Statement: guidelines for reporting observational studies, guided the reporting of this study. (16) Most of the survey was comprised of quantitative items; however, there also were three open-ended questions to glean more in-depth information about appropriateness of skin cancer risk-reducing activities and perceived comfort level with these activities.

\section{Sample}

Eligible for this survey were self-reported licensed or certified currently practicing MTs who had been in practice for three years or more and were 21 years or older. Most states require MTs to be 18 years of age at the time of licensure/certification, thus allowing us to expect eligible MTs to be at least 21 years of age. Excluded from the survey were MTs not selfreporting licensure or certification or current practice. We distributed survey invitation links to MTs in the US using lists from national and state professional massage organizations, posts in trade newsletters, and postings on Facebook and Twitter. We estimated a sample size of 100 was adequate for our survey (based on a population size of $300,000 \mathrm{MTs}$, a $95 \%$ confidence level, and margin of error of $10 \%){ }^{(17)}$ Our sample size calculation determined that we would need to enroll a minimum of 100 respondents to conclude with $95 \%$ confidence that a percentage of the massage therapists agree (or disagree) with each statement, plus or minus $10 \%$. We screened 149 people who accessed the survey for eligibility; 34 were ineligible for being a student, self-reporting that they were not licensed or certified, not practicing, or for submitting blank surveys, leaving 115. Thirteen additional respondents were excluded for incomplete surveys; reasons for nonparticipation were unknown. The final sample was 102 respondents (response rate, $89 \%$ ). After completing the survey, respondents could opt in to a raffle drawing by providing their name and email. Four randomly selected respondents received $\$ 50$ at the end of the study.

\section{Measures}

Participants completed an online survey that required about 15 minutes of their time. We assessed demographics (4 items: age, sex, state(s) where licensed to practice, and ethnicity), personal skin cancer risk (5 items: family history, history of previous skin cancer occurrence, blistering sunburn, and tanning bed use), previous skin cancer education, and practice characteristics (28 items: years of experience, type of practice, client visits [number, length]) with single categorical or interval level scaling. Personal preventive behaviors measured (4 items) were use of sunscreen, wearing hats and sun protective clothing, and limiting time in the sun during each season of the year $(1=$ never to $4=$ always $)$.

We assessed participants' perceptions of appropriateness to ask clients about skin cancer history, sunscreen use, VSA, referral to a doctor for a suspicious lesion and follow-up, and when to have a conversation about sun safety and a suspicious lesion ( 7 items). 
We assessed comfort with recognizing a suspicious lesion, discussing it with a client, recommending a client see a doctor for a suspicious lesion, and sharing skin cancer and UVR protection knowledge with clients (5 items). Item responses were scaled from $1=$ strongly agree to $4=$ strongly disagree or were multiple-choice. In three open-ended questions, respondents could expand responses on the appropriateness of: 1) asking clients about a skin cancer history, 2) asking about sunscreen use, and 3) asking about skin examination during the appointment.

To assess client-related VSA activities over the past year, respondents provided replies to six items regarding whether they had ever noticed a suspicious lesion on a client, and if so, how many times, and resulting action (did they suggest the client see a doctor). One item queried whether clients referred for physician evaluation later confirmed a diagnosis of skin cancer.

\section{Statistical Analysis}

We used descriptive statistics (frequencies, percentages, measures of central tendency) to analyze all items. No missing data strategies were implemented due to low missing values $(n=6)$. Open-ended questions for the respondents were analyzed using established methods for qualitative content analysis. (18) One member of the research team compiled the responses to the open-ended questions in Excel. Three members of the research team used open coding, also managed in Excel, to generate codes from the responses, then categories and subcategories. ${ }^{(18)}$ The team reached consensus on the codes, categories, and subcategories.

\section{RESULTS}

Table 1 lists the characteristics of the sample. The majority were female and non-Hispanic white. Almost one-third (32\%) reported indoor tanning at least once in their lifetime, starting between age 13-35 (average 21). Average personal preventive behaviors were highest in the summer (3.45) and lowest in the winter (2.54). Ten respondents reported a history of nonmelanoma skin cancer.

Table 2 lists the respondents' practice characteristics. Most reported repeat clients throughout the year, client visits of one hour or more, and more than half of the client's skin exposed during the visit. Regarding skin cancer prevention training, 51\% reported receiving skin cancer and/or sun safety education during their MT training. Twenty-two percent reported seeking continuing education on the topics outside of their formal education.

Respondents were more comfortable discussing suspicious lesions and recommending that a client see a doctor than they were sharing knowledge about skin cancer and sun safety (Table 3 ). More respondents
TABLE 1. Demographic Characteristics and Risk Factors

\begin{tabular}{|c|c|}
\hline $\begin{array}{l}\text { Massage Therapists } \\
\quad(n=102)\end{array}$ & \\
\hline Age $($ mean $=44.6$ years, SD 11.53) & $n(\%)$ \\
\hline Female & $93(91)$ \\
\hline \multicolumn{2}{|l|}{ Race/ethnicity } \\
\hline White - non-Hispanic & $84(82)$ \\
\hline White - Hispanic & $5(5)$ \\
\hline Other & $11(11)$ \\
\hline Prefer not to answer & $2(2)$ \\
\hline \multicolumn{2}{|l|}{ States of licensure by US region } \\
\hline West & $48(47)$ \\
\hline South & $20(20)$ \\
\hline Midwest & $28(27)$ \\
\hline Northeast & $20(20)$ \\
\hline \multicolumn{2}{|l|}{ Times used indoor tanning in lifetime } \\
\hline 0 & $32(31)$ \\
\hline $1-4$ & $33(32)$ \\
\hline $4+$ & $28(27)$ \\
\hline History of $4+$ sunburns prior to age 20 & $40(39)$ \\
\hline Diagnosed with a skin cancer & $10(10)$ \\
\hline $\begin{array}{l}\text { Skin cancer prevention is an important health topic } \\
\text { to me personally (yes) }\end{array}$ & $76(74)$ \\
\hline \multicolumn{2}{|l|}{ Frequency of skin self-examination } \\
\hline Every 1-2 Months & $60(64.52)$ \\
\hline Every 3-6 Months & $13(13.98)$ \\
\hline Every 7-12 Months & $13(13.98)$ \\
\hline Never & $7(7.53)$ \\
\hline
\end{tabular}

Personal skin cancer preventive behaviors per season Mean (SD)
Spring

Summer

Fall

Winter
$2.9(0.94)$

$3.45(0.67)$

$2.66(1.03)$

2.54 (1.11) agreed/strongly agreed that it is appropriate to ask a client about skin cancer history, to refer a client to a doctor, and less appropriate to follow up on a referral, ask about sunscreen use, or ask to conduct VSA. The majority reported that the most appropriate time to discuss sun safety and suspicious lesions was at the completion of massage (Table 4). Thirty (29.4\%) responded that they would not discuss sun safety at any time during the massage; two responded that they would not discuss a suspicious lesion at any time.

Over the past year, $80(83 \%)$ of respondents noticed a suspicious lesion on a client during a massage appointment. Of those respondents $11(14 \%)$ spoke to the client about the lesion, $66(83 \%)$ recommended that the client see a health professional about the lesion, and one reported saying nothing to the client. 
TABle 2. Massage Therapists' Practice and Education Characteristics

\begin{tabular}{|c|c|}
\hline Characteristic & Mean (SD) \\
\hline Years working since certification & $11(8)$ \\
\hline Number clients seen per week & $15(10)$ \\
\hline \multirow[t]{2}{*}{ Number new clients seen per week } & $3(4)$ \\
\hline & $n(\%)$ \\
\hline \multicolumn{2}{|l|}{ Number of visits per client per year } \\
\hline $1-10$ & $33(32)$ \\
\hline $11+$ & $69(68)$ \\
\hline Length of client visit ( 1 or more hours) & $96(95)$ \\
\hline Full-time practice & $60(52)$ \\
\hline \multicolumn{2}{|l|}{ Can display educational materials } \\
\hline Lobby & $74(73)$ \\
\hline Treatment room & $78(76)$ \\
\hline Can change intake forms & $84(82)$ \\
\hline $\begin{array}{l}\text { Work in location that offers other cosmetic or skin } \\
\text { care services }\end{array}$ & $30(29)$ \\
\hline Work in location that offers tanning services & $3(3)$ \\
\hline \multicolumn{2}{|l|}{$\%$ of client's skin exposed during massage } \\
\hline$<25 \%$ & $7(7)$ \\
\hline $25-50 \%$ & $6(6)$ \\
\hline $50-75 \%$ & $34(33)$ \\
\hline$>75 \%$ & $55(54)$ \\
\hline \multicolumn{2}{|l|}{$\begin{array}{l}\text { Previous education/training on skin cancer or } \\
\text { sun safety }\end{array}$} \\
\hline Education during massage training & $52(51)$ \\
\hline Continuing education & $22(22)$ \\
\hline
\end{tabular}

Respondents recommended an average of three clients per year to see a doctor for a suspicious lesion. Most respondents reported not knowing the outcome of a physician visit.

Qualitative content analysis of the open-ended questions provided more in-depth perceptions of appropriateness and importance for incorporating skin cancer risk reduction into respondents' practice. Two major categories emerged from the responses: For the Client's Benefit, and Scope of Practice.

The first category, For the Client's Benefit, was defined as respondents' perception of MTs' skin cancer risk-reduction activities and behaviors that have a direct benefit on the client. The subcategories were the following:

- Knowledge of skin cancer history helps modify treatment and is important for client safety.

Several respondents indicated that if the condition is current, it is a contraindication to perform massage, which can incur local and systemic damage to the body. One participant summed up the general thinking about this subcategory:
"... I need to know if they have anything removed, so we can potentially address scar tissue. If someone is being treated for it and is using a topical, I need to be aware (obvious reasons), and if someone is in the process of finding out if they have skin cancer, it's important for me to chart this and get the whole health picture, as well as the mental state of the client."

- Transparency about intentions, including asking permission to assess the skin during a massage.

One respondent stated, "We ask permission before touching or viewing the body, so in this case it would be appropriate to ask clients before examining their skin during an appointment."

- MTs have eyes on skin and can notice changes over time.

Respondents strongly agreed that MTs are likely to see more skin more often than a dermatologist, and also can see parts of the skin that are difficult for others to visualize. "We normally can see places on the body that the client cannot always easily see, [like the] back, scalp, bottom of feet ..." MTs can see changes over time that others may miss.

- MTs have a professional and ethical duty to assist clients with skin assessment.

One participant commented:

"We have a professional duty to assist clients in identifying high-risk marks and areas on their skin. It's possible we're the only people who could catch a questionable spot if they're not receiving screenings through their health care provider."

Another stated: "I cannot 'unsee' what I've seen and I think it would be unethical of me to withhold my concern from them."

The second category was Scope of Practice. Respondents were divided about where skin cancer prevention activities fit within the scope of practice. A few thought that both taking a skin cancer history and asking about skin cancer prevention behaviors were outside of their scope of practice. Subcategories were:

- MTs should take a complete and accurate health history.

One respondent stated that, "This is part of the job and a given." Respondents indicated that the health history should query clients about any type of medical conditions, including any type of cancer; "... it is part of client assessment," and it is a "part of my job."

- The equivocal nature of asking about skin cancer history. 
Table 3. Perceptions of Massage Therapist Appropriateness and Comfort for Skin Cancer Prevention Conversations

\begin{tabular}{|c|c|c|c|c|c|}
\hline & Mean $(S D)^{a}$ & $\begin{array}{c}\text { Strongly Agree } \\
(n, \%)\end{array}$ & $\begin{array}{l}\text { Agree } \\
(n, \%)\end{array}$ & $\begin{array}{l}\text { Disagree } \\
(n, \%)\end{array}$ & $\begin{array}{c}\text { Strongly Disagree } \\
(n, \%)\end{array}$ \\
\hline \multicolumn{6}{|l|}{ Comfort with: } \\
\hline Recommending visit to doctor & $1.52(0.63)$ & $50(54 \%)$ & $38(41 \%)$ & $4(4 \%)$ & $1(1 \%)$ \\
\hline Discussing suspicious lesion & $1.83(0.74)$ & $30(32 \%)$ & $52(56 \%)$ & $7(8 \%)$ & $4(4 \%)$ \\
\hline Sharing sun safety knowledge & $2.06(0.79)$ & $21(23 \%)$ & $50(54 \%)$ & $17(18 \%)$ & $5(5 \%)$ \\
\hline Sharing skin cancer knowledge & $2.12(0.88)$ & $23(25 \%)$ & $43(46 \%)$ & $19(20 \%)$ & $8(9 \%)$ \\
\hline \multicolumn{6}{|l|}{ Appropriateness: } \\
\hline Refer to doctor for suspicious lesion & $1.47(0.61)$ & $55(59 \%)$ & $32(34 \%)$ & $6(6 \%)$ & 0 \\
\hline Follow-up & $2.77(1.57)$ & $40(43 \%)$ & $47(50 \%)$ & $6(6 \%)$ & 0 \\
\hline Ask about skin cancer history & $1.68(0.70)$ & $44(44 \%)$ & $47(47 \%)$ & $8(8 \%)$ & $2(2 \%)$ \\
\hline Ask about SSE & $2.21(0.67)$ & $11(11 \%)$ & $59(60 \%)$ & $26(26 \%)$ & $3(3 \%)$ \\
\hline Ask about sunscreen use & $2.30(0.71)$ & $13(13 \%)$ & $46(46 \%)$ & $39(39 \%)$ & $2(2 \%)$ \\
\hline Ask to examine clients' skin & $2.27(0.82)$ & $18(18 \%)$ & $40(41 \%)$ & $35(36 \%)$ & $5(5 \%)$ \\
\hline Personal importance of topic & $1.94(0.08)$ & $26(28 \%)$ & $50(54 \%)$ & $14(15 \%)$ & $3(3 \%)$ \\
\hline
\end{tabular}

aMean: 1 = strongly agree; 2 = agree; 3 = disagree; 4 = strongly disagree.

TABle 4. Massage Therapists' Perceptions Regarding When, During the Appointment, to Discuss Sun Safety and Suspicious Lesions

At what point in the massage therapy appointment is it appropriate to have a conversation about:

\begin{tabular}{lcc}
\hline & $\begin{array}{c}\text { Sun Safety } \\
(n, \%)\end{array}$ & $\begin{array}{c}\text { Suspicious Lesion } \\
(n, \%)\end{array}$ \\
Before appointment begins & $26(25.49)$ & $15(14.71)$ \\
$\begin{array}{l}\text { During massage treatment } \\
\text { After massage is over }\end{array}$ & $20(19.61)$ & $62(60.78)$ \\
$\begin{array}{l}\text { After appointment ends } \\
\text { I would not discuss this at } \\
\text { any time }\end{array}$ & $07(46.08)$ & $63(61.67)$ \\
\hline
\end{tabular}

Some respondents stated that they need to be aware and fully informed about what is happening with their clients' skin and to see if they are taking care of their skin. One respondent commented: "Knowing if a client is self-examining skin would give an indication of how much he or she knows about any suspicious skin lesions." Others responded that asking about skin cancer history is a question only suitable for dermatologists or oncologists, and maybe estheticians. "Massage therapy has absolutely no bearing on potential carcinomas apart from asking a client if they're aware of a discolored region of their skin and. if not, suggest they see a doctor to have it checked."

- Scope of practice regarding preventive behaviors.

"I think it's okay to ask if a person uses sunscreen, but am not sure where I would go with it if they said no ..."
However, some respondents viewed discussions of sunscreen as being outside their scope of practice and more appropriate for an esthetician to discuss.

"It is not appropriate to bring up or discuss what a client chooses in terms of personal care products. Sunscreen falls into this category and is considered a boundary issue. I am a manual therapist, not an esthetician."

- Not trained to diagnose

"I always let clients know that I will not diagnose but will let them know if I see something that might need closer examination."

\section{DISCUSSION}

An average of $19 \%$ of adult Americans received at least one massage between 2015 and 2016, and an average of $32 \%$ of adult Americans received a massage in the previous five years. ${ }^{(8)}$ Our respondents saw an average of 15 clients per week; a majority of those clients returned to their MT 11 times per year for a one-hour massage. These findings further support developing interventions targeting MTs as partners in skin cancer prevention to help decrease the public health burden of skin cancer. However, MTs and the profession also need to support such a partnership effort.

A key finding from this study was that the majority of respondents were amenable to having skin cancer prevention conversations before, during or after massage treatments; however, few were engaging in these conversations. One barrier may be low confidence for having a conversation about a 
suspicious lesion, and then recommending referral to a health provider. A majority of respondents felt that it was appropriate to ask about skin cancer history, suggest that clients see a doctor for a suspicious lesion, and ask about follow-up for suspicious skin lesions. One respondent stated: "We may be able to notice a suspicious spot and refer them to the appropriate practitioner." However, 80 respondents had noticed a suspicious lesion on the skin, but 24 of those did not recommend seeing a provider. A barrier to making such a recommendation may be a lack of confidence in VSA. This same barrier was noted in the last study of MTs conducted in $2010,{ }^{(15)}$ and as those authors suggested, may be addressed through more skin cancer-focused training.

Training itself is a barrier. Training standards and requirements for massage therapists vary greatly by state and locality. Only half the respondents reported receiving any education on skin cancer prevention during their MT training; fewer (32\%) reported any continuing education. These percentages approximated those in the previous study of MTs (60\% during and $25 \%$ after primary professional education). ${ }^{(15)}$ One respondent stated:

\begin{abstract}
"[In massage therapy training] we spend only 1 or 2 days out of 1,500 hours on skin conditions. Many therapists can't recognize even major musculoskeletal disorders ... let alone skin issues."
\end{abstract}

There is a need to establish efficacy of training MTs to engage in conversations about these topics, particularly given popular press stories of MTs' involvement in detecting melanoma. ${ }^{(15,19)}$ In order to maximize its public health potential, MT training should incorporate evidence-based methods for skin cancer risk reduction suitable for the MT practice context, and content on client-centered communication and referral skills. Our respondents perceived that continuing education training with attached continuing education units likely would generate more interest among MTs.

Respondents mentioned scope of practice frequently in the open-ended responses. In the massage therapy profession, scope of practice varies from state to state. However, among state laws, there are common elements pertaining to the scope of practice for massage therapy: 1) massage therapy involves the manipulation of soft tissue; 2) this soft-tissue manipulation should have a specific therapeutic intent or purpose. ${ }^{(20)}$ Beyond these two major elements, there is legislative and professional discrepancy that may engender confusion about scope of practice. $(20,21)$ However, most respondents perceived that discussions about skin lesions are within their scope of practice. In contrast, many respondents considered sharing skin cancer and sun protection knowledge as outside the scope of practice; almost one-third of respondents felt it was not appropriate to discuss sun safety at any time. "Client education" is an established part of MT scope of practice. ${ }^{(22)}$ Partnering with MTs for skin cancer prevention will have to consider how education for clients with visible sun damage fits into the scope of MT practice.

\section{Limitations}

This study was limited by recall bias based on many years that may have elapsed between MTs' training and completion of the survey. We only included licensed/certified and practicing MTs which removed those closer to their training graduation dates. However, we were not able to verify licensure or certification and thus were limited by self-report. Although we enrolled MTs from various sources throughout the US, we were only able to get 102 full survey responses, diminishing generalizability of the findings.

\section{CONCLUSION}

The Surgeon General recommended partnering with community and business to reduce the skin cancer burden in the US. MTs could be potentially ideal partners based on the quality and frequency of contact with their clients, some of whom may have visible risk factors for skin cancer. MTs in various regions throughout the US also appear to have boundaries for content to include in a client discussion and remain in their scope of practice. This study generated preliminary data about MTs perceptions of the appropriateness for including client-focused skin cancer risk-reduction activities in their practice, as well as their comfort level with these activities. These findings provided support for a current study testing an intervention for MTs to learn about and incorporate skin cancer risk-reduction messages and activities into their practice.

\section{ACKNOWLEDGMENTS}

This project was supported by a grant from the Skin Cancer Institute at the University of Arizona Cancer Center, Tucson, AZ. Dr. Loescher's contribution was in part supported by the National Cancer Institute of the National Institutes of Health under award number P30 CA023074 (Behavioral Measurement and Intervention Shared Resource).

\section{CONFLICT OF INTEREST NOTIFICATION}

The authors declare there are no conflicts of interest. The Skin Cancer Institute did not have any role in the study design; collection, analysis, and interpretation of data; writing the report; or the decision to submit the report for publication. 


\section{COPYRIGHT}

Published under the CreativeCommons AttributionNonCommercial-NoDerivs 3.0 License.

\section{REFERENCES}

1. Rogers HW, Weinstock MA, Feldman SR, Coldiron BM. Incidence estimate of nonmelanoma skin cancer (keratinocyte carcinomas) in the US population, 2012. JAMA Dermatol. 2015;151(10):1081-1086.

2. National Cancer Institute. Fast StatsaAn interactive tool for access to SEER cancer statistics. Bathesda, MD: National Cancer Institute; 2015. Available from: http://seer.cancer.gov/ faststats. Accessed on November 25, 2015.

3. Guy GP, Jr., Machlin SR, Ekwueme DU, Yabroff KR. Prevalence and costs of skin cancer treatment in the U.S., 2002-2006 and 2007-2011. Am J Prev Med. 2015;48(2):183-187.

4. International Agency for Research on Cancer (IARC). IARC Monographs on the Evaluation of Carcinogenic Risks to Humans. Vol. 55: Solar and ultraviolet radiation. Lyon, France: IARC; 1992.

5. Balch CM, Gershenwald JE, Soong SJ, Thompson JF, Atkins MB, Byrd DR, et al. Final version of 2009 AJCC melanoma staging and classification. J Clin Oncol. 2009;27(36):6199-6206.

6. Green AC, Baade P, Coory M, Aitken JF, Smithers M. Population-based 20-year survival among people diagnosed with thin melanomas in Queensland, Australia. J Clin Oncol. 2012;30(13):1462-1467.

7. US Department of Health \& Human Services. The Surgeon General's Call to Action to Prevent Skin Cancer. Washington, DC: Office of the Surgeon General; 2014.

8. American Massage Therapy Association. Massage Therapy Industry Fact Sheet. Evanston, IL: AMTA; 2017. Available from: https://www.amtamassage.org/infocenter/economic_industryfact-sheet.html Accessed on October 15, 2017.

9. Tsao H, Weinstock MA. Visual inspection and the US Preventive Services Task Force Recommendation on Skin Cancer Screening. JAMA. 2016;316(4):398-400.

10. Oliveria SA, Heneghan MK, Cushman LF, Ughetta EA, Halpern AC. Skin cancer screening by dermatologists, family practitioners, and internists: barriers and facilitating factors. Arch Dermatol. 2011;147(1):39-44.

11. Roosta N, Black DS, Wong MK, Woodley DT. Assessing hairdressers' knowledge of scalp and neck melanoma and their willingness to detect lesions and make referrals to dermatologists. J Am Acad Dermatol. 2013;68(1):183-185.
12. Turrisi R, Gunn H, Hultgren B, Warner N, Mallett KA. The style project: feasibility of collaborating with salons for prevention and early detection of skin cancer. Arch Dermatol. 2012;148(10):1206-1207.

13. Nahin RL, Barnes PM, Stussman BJ, Bloom B. Costs of complementary and alternative medicine (CAM) and frequency of visits to CAM practitioners: United States, 2007. Natl Health Stat Report. 2009(18):1-14.

14. Cherkin DC, Deyo RA, Sherman KJ, Hart LG, Street JH, Hrbek A, et al. Characteristics of visits to licensed acupuncturists, chiropractors, massage therapists, and naturopathic physicians. J Am Board Fam Pract. 2002;15(6):463-472.

15. Campbell SM, Louie-Gao Q, Hession ML, Bailey E, Geller AC, Cummins D. Skin cancer education among massage therapists: a survey at the 2010 meeting of the American Massage Therapy Association. J Cancer Educ. 2013;28(1):158-164.

16. von Elm E, Altman DG, Egger M, Pocock SJ, Gatzsche PC, Vandenbroucke JP. The Strengthening the Reporting of Observational Studies in Epidemiology (STROBE) statement: guidelines for reporting observational studies. J Clin Epidemiol. 2008;61(4):344-349.

17. Daniel WW. Biostatistics: A Foundation for Analysis in the Health Sciences, 7th edition. New York: John Wiley \& Sons; 1999.

18. Elo $\mathrm{S}$, Kyngas $\mathrm{H}$. The qualitative content analysis process. $J$ Adv Nurs. 2008;62(1):107-115.

19. Neufeld A, Anderson SK. Massage therapists and the detection of skin cancer in clients. Massage Today. 2013;13(2).

20. Cael C. Scope of Practice: Safe and Effective Application Techniques. In: Massage and Bodywork Magazine for the Visually Impaired. Golden, CO: Associated Bodywork \& Massage Professionals; 2009. Available from: https:/www.abmp.com/ textonlymags/article.php?article $=347$

21. Kennedy AB, Cambron JA, Sharpe PA, Travillian RS, Saunders RP. Clarifying definitions for the massage therapy profession: the results of the Best Practices Symposium. Int J Ther Massage Bodywork. 2016;9(3):15-26.

22. Federation of State Massage Therapy Boards. Model Massage Therapy Practice Act, first edition. Overland Park, KS: FSMTB; 2014.

Corresponding author: Lois $\mathrm{J}$. Loescher, $\mathrm{PhD}$, RN, College of Nursing, University of Arizona, 1305 N Martin Ave., Tucson, AZ, USA 85721

E-mail: loescher@email.arizona.edu 